\title{
Research Paper: Evaluation of Positive and Negative Affect Induction on the Regional Brain Activity and Personality Traits
}

\author{
Hamid Radsepehr ${ }^{1} \odot$, Hossein Shareh ${ }^{2 *}$, Alemeh Dehnabi $^{3} \mathrm{C}$ \\ 1. Department of Psychology, Neyshabour Branch, Islamic Azad University, Neyshabour, Iran. \\ 2. Department of Psychology, Hakim Sabzevari University, Sabzevar, Iran. \\ 3. Department of Nursing, Faculty of Jovein School of Nursing, Sabzevar University of Medical Sciences, Sabzevar, Iran.
}

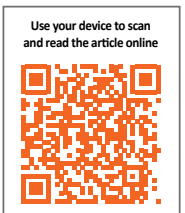

ditation: Radsepehr, H., Shareh, H., \& Dehnabi, A. (2019). Evaluation of Positive and Negative Affect Induction on the Regional Brain Activity and Personality Traits. Journal of Practice in Clinical Psychology, 7(2), 95-106. http://dx.doi.org/10.32598/jpcp.7.2.95

http://dx.doi.org/10.32598/jpcp.7.2.95

(c) 03

Article info:

Received: 12 Oct 2018

Accepted: 28 Jan 2019

Available Online: 01 Apr 2019

Keywords:

Brain waves, Personality inventory, Affect.

\section{ABSTRACT}

Objective: The present study aims to investigate the effect of emotions (negative and positive affects) and gender on the activity of different brain regions and their relationship with personality traits of extraversion, introversion, neuroticism, and stability.

Methods: The study participants were 33 right-handed volunteer undergraduate students (17 males and 16 females). Our stimuli were two 6-minute long happy and sad video clips. We used electroencephalography for brain imaging. Briggs-Nebes handedness questionnaire, Eysenck personality inventory, general health questionnaire, and positive and negative affect schedule questionnaire were used for assessing participants' reactions. The collected data were analyzed by MANOVA and ANOVA tests.

Results: Different activities due to positive and negative affect inductions were seen only in right temporal (Sig. $=0.036, \mathrm{~F}=3.453$ ), left temporal $(\mathrm{Sig} .=0.045, \mathrm{~F}=2.873)$, right posterior (Sig. $=0.032, \mathrm{~F}=3.157$ ) and left posterior lobes of the participants' brains (Sig. $=0.014 ; \mathrm{P}<0.01$, $\mathrm{F}=2.932$ ). Under positive affect induction, the activity of right temporal lobe in extraverted people was higher than that in introverted ones. No significant difference was found in the right anterior and right posterior activities between stable and neurotic individuals under negative attitude induction $(\mathrm{F}=0.387, \mathrm{P}>0.05)$. There was no significant difference of activity in the left anterior of stable and neurotic subjects under negative attitude induction $(\mathrm{P}>0.05)$. Also, there was no significant difference between male and female students' brain activity $(\mathrm{P}>0.05)$.

Conclusion: Therefore, regional brain activity is different under positive attitude and negative attitude inductions, but gender does not affect it. Also, personality traits are effective in the activity of some brain regions.

$*$ Corresponding Author:

Hossein Shareh, $P h D$

Address: Department of Psychology, Hakim Sabzevari University, Sabzevar, Iran.

Tel: +98 (912) 4242757

E-mail: hsharreh@yahoo.com.au 


\section{Highlights}

- Under positive affect induction, the activity of the right posterior region of the brain (right temporal lobe) is higher in extraverted people.

- Activities of the right anterior and posterior regions are not different in stable and neurotic people under the negative affect.

- Brain activities of introverted and extraverted people are similar to each other in the right anterior region of the brain under negative affect induction.

- There is no significant difference in left anterior activity of stable and neurotic participants under positive affect induction.

- There is no significant difference in the brain activity of male and female students under the negative affect and positive affect.

\section{Plain Language Summary}

We aimed to investigate the relationship between positive affect and negative affect induction, gender, and regional brain activity based on Eysenck theory to predict differences in regional patterns of electroencephalography associated with personality traits. Our study indicates that the activity pattern of all areas of the brain changes in processing different emotional states, but some regions show more changes, which indicates the specificity of emotional processing location. According to the results, right hemisphere and particularly posterior regions are more involved in processing negative affects. Also, the personality dimension of individuals can affect the activity of some regions such that extraversion, compared to introversion, is associated with the reduction of cortical activity in right brain hemisphere. Thus, the regional brain activity under positive and negative affect inductions is different, but gender does not affect brain activity. Also, personality traits can affect the function of some brain regions.

\section{Introduction}

xcitement is a psychological structure 1 which coordinates four dimensions of feeling, arousal, purpose, and expression in a coherent and adaptive pattern (Reeve, 2007). Typically, emotions are created in people as reactions to important situational events. These feelings are either positive or negative affects, which are independent states and not contradictory feelings (Revelle \& Scherer, 2008). Emotion consists of a combination of feeling, action, appraisal, and desires at a specific time and location; hence, personality includes the integration of these components over time and space (Revelle \& Scherer, 2011).

In personality psychology, dimensions of personality include reliable and stable behavioral tendencies at the time and in various situations (Eysenck \& Eysenck, 1994). Personality consists of a pattern of emotion, behavior, cognition, and desires (goals) in various situations of time and space (Revelle \& Scherer, 2011). Al- though there is no agreement among researchers on the number of characters necessary to describe a personality, they all agree on the two general categories of extravert and neuroticism (Gomez \& Gomez, 2002). Eysenck declared that an individual's personality could be defined by two dimensions of (E) extraversion/introversion and (N) neuroticism/stability (Eysenck, 1974).

Different people show various responses to emotional stimuli. Recently, asymmetrical activation of the frontal cortex which has been regarded as one of the distinct individual differences (Hamann \& Canli, 2004) affecting emotion processing, has been scrutinized (HarmonJones, Lueck, Fearn, \& Harmon-Jones, 2006). Electroencephalography has been known as a non-invasive technique to investigate the individual characteristics and comprehend better the neurophysiological processes related to neuroticism and emotions in general. According to the studies on neuroimaging and electrophysiology-based methods, Event-Related Potentials (ERPs) are changed by the personality types, especially by neuroticism (Georgiev, Minchev, Philipova \& Christova, 
2008). Some examinations conducted on brain activity using Electroencephalography (EEG) indicate that frontal asymmetries are rigorously related to dispositional mood, temperament, psychopathology, and reactivity to emotion-eliciting stimuli (Davidson, 1992; Tomarken, Davidson, Henriques, 1990).

In an investigation, Dehnabi, Radsepehr \& Shareh (2017) showed that in the extroverts, there was an asymmetric temporal and parietal lobes activity of the EEG waves at rest, and in the introverts, there was an asymmetric temporal lobe activity. Also, they found a remarkable relationship between asymmetric temporal lobe activities in the neurotic-stable personality trait. Therefore, because of the existing difference in mean absolute alpha power in both groups, the left hemisphere around this lobe shows more activity in both groups. According to Azami et al. (2013) study on cortical brain activity change patterns in extraversion and neuroticism, there was a remarkable inverse relationship between the extraversion and activities of posterior, frontal, and right temporal areas in basic status. It has been shown that at the basic status, men's brain had more activities in right anterior, temporal, and posterior areas than women's brains (Azami, Makvand Hosseini, Dokani \& Zamirinejad, 2013).

The results of Pascalis et al. study on EEG-alpha asymmetry, Behavioral Inhibition System BIS/ Behavioral Activation System (BAS), and dispositional optimism, indicate that there was significant associations between resting posterior frontal delta and theta activity with personality traits. The higher BAS would result in the greater left-sided activation in the middle frontal gyrus (BA11). Higher activations in the left-superior frontal gyrus (BA10) and the right posterior cingulate cortex (BA31) were found related to optimism (Pascalis, Cozzuto, Caprara \& Alessandri, 2013). In their study on EEG-alpha asymmetry and positive personality traits, Alessandri, Caprara \& Pascalis (2015)found a remarkable and unique association between Personality Dimension of Positivity (POS) scores and the posterior right hemisphere activation in the BA23 and BA31 Brodmann areas. In a recent investigation, it has been shown that there is a possibility of modulating the neural activities at the basic levels of affective processing by personal traits, like neuroticism or mindfulness, which are associated to more problems in emotion regulation or more healthy emotional functioning, respectively (Brown, Goodman \& Inzlicht, 2013).

These brain activity studies are mainly focused on the overall activity of the cerebral cortex, and is less ad- dressed as a combination of a personality model with emotional models and brain activity. On the other hand, some studies have not succeeded in finding the connection between the excitement and activity of other areas. Therefore, in this study, while considering Eysenck's theory, we focused on studying the central nervous system about excitement and personality. In this paper, we aimed to investigate the relationships among Positive Affect (PA) and Negative Affect (NA) induction, gender, and regional brain activity based on Eysenck's theory of personality to predict differences in regional patterns of EEG associated with personality traits.

\section{Methods}

The present study applies positive and negative affect induction method to investigate its impact on EEG waves activity recorded from the brain of each participant. The study participants were 33 healthy right-handed undergraduate volunteer students (17 males and 16 females) aged 19 to 29 years who were studying in different majors in Payam-e Noor University of Sabzevar City, Iran during the academic year 2013-2014. For sampling, first, from a statistical population of 450 students, 36 participants were selected for the study who their General Health Questionnaire (GHQ-28) scores were lower than 23 and Eysenck's Personality Inventory (EPI) scores lower than 6 . The participants were right-handed and had no history of illness (inclusion criteria). They were divided randomly into two groups with PA induction, and NA induction each with 18 members ( 9 males and 9 females). During the study, one male and one female student from negative induction group, and one female student from positive induction group left the study. As a result, the number of participants became 33 students, 16 in the NA group ( 8 females and 8 males) and 17 in the PA group ( 9 males and 8 females). Written consent was obtained from all of them.

General Health Questionnaire was developed by Goldberg (1978), and used to measure the prevalence of psychiatric disorders. It has four subscales: somatic symptoms (questions 1-7), anxiety (questions 8-14), social withdrawal (questions 15-21), and depression (questions 22-28). Different research studies have suggested different cut-off scores. Palahang conducted an initial assessment of the GHQ-28 to prepare it for an epidemiological study in Kashan City, Iran, with a sample of 80 people. With the cut-off point of 22, the sensitivity, specificity, efficiency, and total error of classification of the test were $0.20,0.80,0.74,0.88$, respectively (Palahang, Nasr, Baraheni, Shahmohammadi, 1995). In this research, the cut-off score was 23 . To determine the validity of the 
questionnaire, Goldberg and Williams provided 853 questionnaires, and the samples completed them. The internal correlation coefficient was 0.95 , determined by the split-half method (Goldberg, 1988). Taghavi (2001) reported the reliability of the questionnaire by test-retest method (70.0), split-half (0.93), and the Cronbach's $\alpha$ (0.90).

Positive and Negative Affect Schedule (PANAS) is a 20-item questionnaire developed by Watson, Clark \& Tellegan (1988). The items are scored based on a 5-point scale: $1=$ very slightly or not at all, $2=$ a little, $3=$ =moderately, $4=$ quite a bit, and $5=$ very much. It measures positive affect and the negative affect modes each with 10 items. The overall range of scores for each subscale is 10 to 50 . The validity of the test (in test-retest method) has been reported for the positive affective subscale as 0.68 and for the negative subscale as 0.71 (Watson et al., 1988). Abolghasemi obtained the coefficient of correlation between its components and the total scale from 0.74 to 0.94 (Abolghasemi, 2009). We used the Persian version of this questionnaire first for measuring the effectiveness of the study stimuli, and then for the main measurement (EEG) in three steps: a. when subjects enter into the EEG room; b. After first 6 min of EEG recording; and c. After showing stimuli.

Eysenck's Personality Inventory was developed by Eysenck \& Eysenck, (1985). It assesses the personality traits of a person. Its short form has 57 items answered by "Yes" or "NO", with three dimensions: E (Extraversion), N (Neuroticism), and P (Psychoticism). A fourth dimension, the $\mathrm{L}$ (Lie scale), was introduced later to measure to what extent subjects were deliberately attempting to control their scores. In our study, we used only the $\mathrm{E}$ and $\mathrm{N}$ scales.

To determine the reliability and validity of this questionnaire, Eysenck implemented it on a single unit in two periods and obtained its validity and reliability. The internal validity coefficients (Cronbach's $\alpha$ ) for men were 0.78 for $\mathrm{P}, 0.90$ for $\mathrm{E}, 0.88$ for $\mathrm{N}, 0.88$ for $\mathrm{L}$. These values for women were 0.76 for $\mathrm{P}, 0.85$ for $\mathrm{E}, 0.85$ for $\mathrm{N}$, and 0.79 for $\mathrm{L}$. For the Iranian samples, the reported values for coefficient of validity found by a test-retest method (within two months) are as follows: $\mathrm{P}=0.72$, $\mathrm{N}=0.8, \mathrm{E}=0.92$, and $\mathrm{L}=0.88$ (Kaviani, Pour Naseh, Moosavi, 2005). There are two options for each subscale of the questionnaire: "Yes" or "No".

Two video clips were used as stimuli; happy (positive) and sad (negative). Each clip lasted 6 minutes and showed to the participants on a computer monitor. It should be noted that these video clips were made from 10 clips downloaded from the Internet. The 16-channel V-Amp device under windows XP-2000 operating system was used for recording EEG. Through putting the electrodes on the scalp, the electrical activity of the brain was recorded in the EEG method. There have been two types of caps: wired and wireless. In this study, the 10-20 International system was applied for naming and electrode positioning where the letters $\mathrm{F}, \mathrm{T}, \mathrm{C}, \mathrm{P}$, and $\mathrm{O}$ indicate frontal, temporal, central, parietal, and occipital lobes, respectively. Also, FP represents the prefrontal point on the skull. To check the exact location of electrodes and determine the resistance of each electrode, actiCAP control software was used.

After placing 16 electrodes and two reference and ground electrodes, the participants were asked to avoid teeth grinding, not to cross their legs, have less blinking, and swallow their mouth water. After this phase, we used the Brain Vision Recorder to record the waves. To do this, after specifying the location of EEG files, amplifier parameters, and choosing the number of channels show $(n=16)$, we set the filter parameters as follows: notch filter $=50 \mathrm{~Hz}$, low cutoff filter $=1 \mathrm{~Hz}$, and high cutoff filter $=50 \mathrm{~Hz}$. After saving the workspace file, for setting segmentation parameters, we selected the option "divide data set in equal size segments". The segment interval length was defined as $30 \mathrm{~s}$ (based on time) and let the option "overlap segments" remained unchecked. All artifacts were rejected manually. We used the difference criterion for this purpose.

It should be noted that during wave recording in both normal and induced state (each had twelve 30-second items), the eyes of the participants were open. After recording, by using Brain Vision analyzer and FFT option, brain waves were converted from amplitude versus time to amplitude versus frequency, and as a result, Absolute Power (AP) of alpha bands for each region was computed. Analyzer Test tool was employed for preparing these data for statistical analysis. This software is an EXCELbased application designed for averaging numerical data based on alpha, beta, delta, and infra-delta EEG waves. According to the setting, the resolution frequency was $0.004 \mathrm{~Hz}$

Table 1 presents the frequency range of the waves. The calculated mean values for channels and EEG waves were obtained from 131072 samples taken from each channel. Then, the obtained mean values of alpha waves were input to SPSS to assess the mean alpha waves in each channel at normal and induced states. Overall, the time spent on each participant for EGG recording and analysis was 2 hours. In 
the end, for each subject, 16 alpha AP means for 16 channels were calculated. Before conducting the research, the study procedure was explained to the participants, and informed consent was received from them. Before using stimuli (first phase of the preliminary study), the participants were asked to fill in the handedness questionnaire. Then we assessed the right-handed participants using the GHQ-28 scale. As a result, among 33 subjects, 9 subjects whose GHQ-28 score was lower than 23 , and 4 left-handed subjects were removed. The final 20 participants were divided into two groups: PA and NA, each including 5 males and 5 females.

The participants were asked to express their current mood (before watching clips) by filling in the PANAS questionnaire. Afterward, they were asked to sit at their computers and focus their attention only on the screen. Also, we provided headphones for the participants to avoid the influence of noise. After watching the clips (second phase of the preliminary study), they were asked to fill in the PANAS questionnaire again. After completing the task and collecting data, we tested the induction effects of the two stimuli by t-test. After stimulating the participants by displaying happy and sad video clips to them, the participants were asked to fill the PANAS questionnaire both before EGG recording and after recording waves in both normal and induced states. Considering that the EEG recording was conducted in two states, we analyzed our hypothesis using ANOVA and MANOVA tests.

It should be noted that the presented data in the results section indicates the mean alpha AP, not the activity rate of the brain regions. This raw data (AP) are inversely related to brain activity (Allen, Mcknight, Moreno, Demeree, \& Delgado, 2009). Also, since some studies report the adverse effects of eyes and eyelid activities on the data of Frontal Polar Cortex (FPC), the author investigated brain activity once with the presence of FPC and once without its presence.

\section{Results}

Descriptive statistics of the participants' personality traits based on different brain regions

Table 1 presents the Mean \pm SD for the personality traits of the participants based on their different brain regions.

\section{The effects of stimuli on the participants}

We used the paired t-test to examine whether the effects of happy and sad video clips could induce positive and negative affects to the participants. According to the $\mathrm{t}$-test results, for the sad video clip $\mathrm{t}=-4.19, \mathrm{df}=9$, and $\mathrm{P}<0.01$, and for the happy video clip $\mathrm{t}=-6.517, \mathrm{df}=9$, and $\mathrm{P}<0.000$. These results indicate a good induction.

\section{Testing research hypotheses}

There were presumptions of the MANOVA test, including normality, homogeneity of variance-covariance, and the correlation between dependent variables. MANOVA test results showed that only alpha AP of the right temporal lobe was significantly different under PA induction in introverted and extraverted individuals and no significant difference was found between electrode locations in left anterior and right posterior areas. Also, only T8 scalp electrode location reported a significant difference of alpha AP among introverted and extraverted subjects (Sig. $=0.043 ; \mathrm{P}<0.05 ; \mathrm{F}=0.60)$ (Table 2).

MANOVA test results showed no significant difference between neurotic and stable subjects in mean alpha AP in right anterior and right posterior $(\mathrm{P}>0.05)$ (Table 3$)$. According to ANOVA test results, there was not any significant difference among electrode locations of Fp2, F4, F8 in right anterior of introverted and extraverted subjects $(\mathrm{P}>0.05)$ (Table 4). ANOVA test results showed no significant difference of alpha AP among electrode locations of the left anterior area in stable and neurotic subjects under PA induction $(\mathrm{P}>0.05)$ (Table 5). MANOVA test results reported significant difference of mean alpha AP only in right temporal (Sig. $=0.036 ; \mathrm{P}<0.01 \mathrm{P} ; \mathrm{F}=3.453$ ), left temporal (Sig. $=0.045 ; \mathrm{P}<0.05 ; \mathrm{F}=2.873$ ), right posterior (Sig. $=0.032 ; \mathrm{P}<0.01 ; \mathrm{F}=3.157$ ) and left posterior lobes of participants (Sig. $=0.014 ; \mathrm{P}<0.01 ; \mathrm{F}=2.932$ ) under induced PA and NA states (Table 6). MANOVA test results reported no significant difference between males and females under PA and NA induction $(\mathrm{P}>0.05)$ (Table 7, Table 8).

\section{Discussion}

In this study, we found out that under PA induction, the activity of the right posterior region of the brain (right temporal lobe) in extraverted people is higher than that in introverted ones, but regarding the left anterior region activity, there was no difference between them. Dehnabi et al. reported that EEG waves at rest showed an asymmetric temporal and parietal lobes activity in the extroverts, and asymmetric temporal lobe activity in introverts (Dehnabi et al., 2017). These findings were in agreement with the results of the Heller study, This is consistent with the findings of Heller suggesting different effects of pleasant and negative affects on regional brain activity (Heller, 1993). In their study, Moghadas Tabrizi \& 


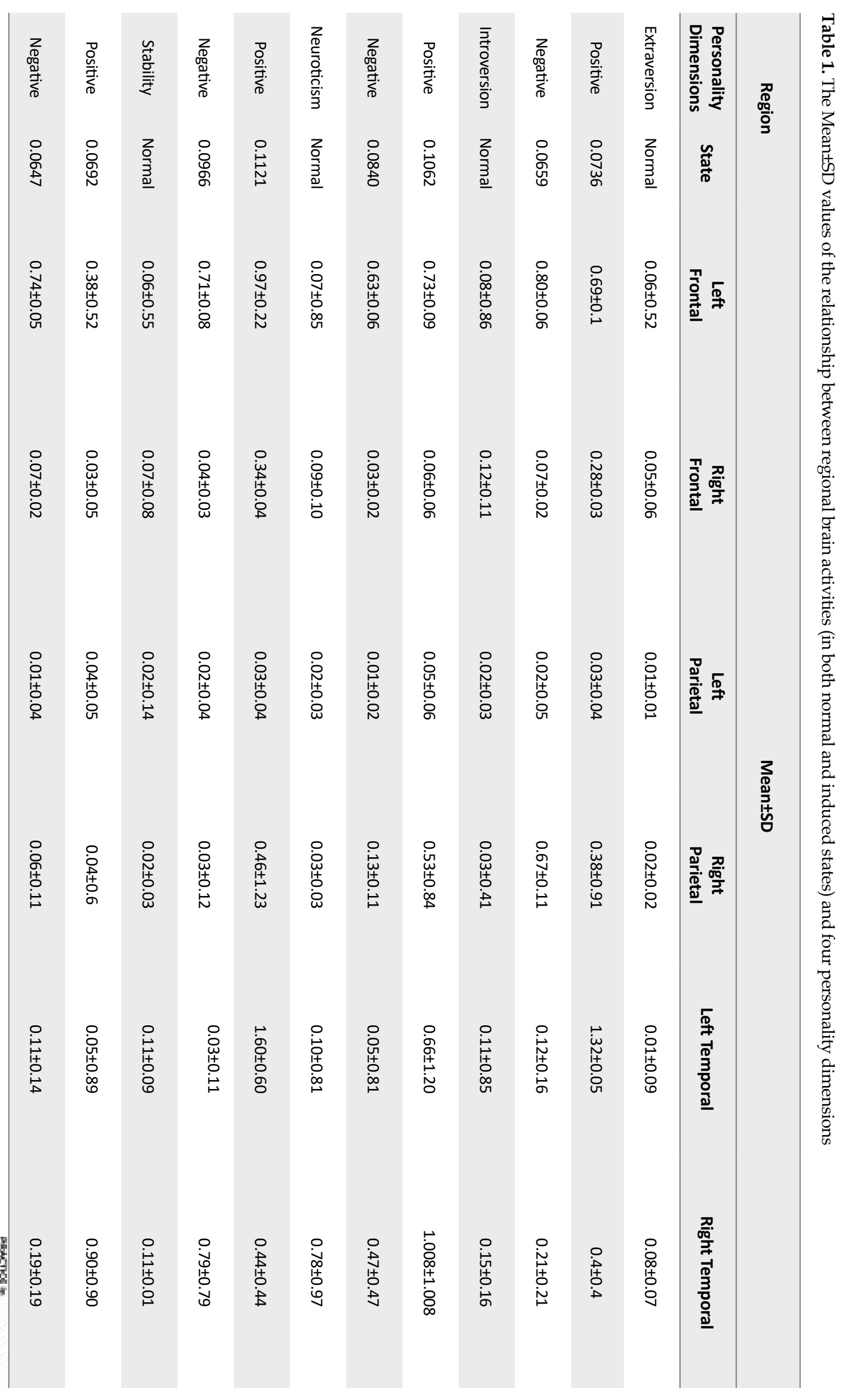


Table 2. MANOVA test results for $\mathrm{H} 1$

\begin{tabular}{|c|c|c|c|c|c|c|}
\hline Brain Sites & & Sum of Squares & df & Mean Squares & $\mathbf{F}$ & Sig. \\
\hline \multirow{3}{*}{ Left anterior } & FP1 & 0.20 & 1 & 0.20 & 2.45 & 0.312 \\
\hline & $\mathrm{F} 7$ & 0.17 & 1 & 0.17 & 1.82 & 0.254 \\
\hline & F3 & 0.74 & 1 & 0.74 & 0.31 & 0.321 \\
\hline \multirow{5}{*}{ Right posterior } & P8 & 1.30 & 1 & 1.30 & 0.38 & 0.205 \\
\hline & $\mathrm{T} 8$ & 0.77 & 1 & 0.77 & 0.60 & 0.043 \\
\hline & P4 & 0.22 & 1 & 0.22 & 0.38 & 0.095 \\
\hline & $\mathrm{C} 4$ & 0.20 & 1 & 0.20 & 0.15 & 0.327 \\
\hline & $\mathrm{O} 2$ & 1.45 & 1 & 1.45 & 0.127 & 0.241 \\
\hline
\end{tabular}

Mesbahi (2015) found an association between left frontal alpha asymmetry (superiority right hemisphere) and depressive symptoms at rest.

Additionally, Alessandri et al. (2015) conducted a study on EEG-alpha asymmetry and positive personality trait and found that POS scores were significantly and uniquely associated with the posterior right hemisphere activation in the BA23 and BA31 Brodmann areas. This finding was consistent with the study conducted by Pascalis et al. (2013) on the field of EEG- $\alpha$ asymmetry, BIS/ BAS, and dispositional optimism. They proved that there were significant associations between resting posterior versus frontal delta and theta activity and personality traits. The results of the study on the induction of mood and brain activity by Fakhari and colleagues indicate an increased activity in the frontal area and left posterior in individuals with high BAS sensitivity in response to neutral stimuli, although there was no significant difference found in the BIS group regarding this position (Fakhari, Rostami, Nazari, Garoosi, \& Farshi, 2012). Therefore, the findings of these studies are similar to those of the present research in different types of personalities. So

Table 3. MANOVA test results of $\mathrm{H} 2$

\begin{tabular}{|c|c|c|c|c|c|c|}
\hline \multicolumn{2}{|c|}{ Brain Sites } & \multirow{2}{*}{$\begin{array}{c}\text { Sum of Squares } \\
0.324\end{array}$} & \multirow{2}{*}{$\begin{array}{l}\text { df } \\
1\end{array}$} & \multirow{2}{*}{$\begin{array}{c}\text { Mean Square } \\
0.324\end{array}$} & \multirow{2}{*}{$\begin{array}{c}\mathbf{F} \\
2.42\end{array}$} & \multirow{3}{*}{$\begin{array}{l}\text { Sig. } \\
0.365\end{array}$} \\
\hline \multirow{6}{*}{ Right anterior } & \multirow{2}{*}{ Fp1 } & & & & & \\
\hline & & 0.054 & 1 & 0.054 & 0.37 & \\
\hline & \multirow{2}{*}{ F7 } & 0.761 & 1 & 0.761 & 1.82 & \multirow{2}{*}{0.854} \\
\hline & & 0.754 & 1 & 0.754 & 26.72 & \\
\hline & \multirow{2}{*}{ F3 } & 1.32 & 1 & 1.32 & 35.24 & \multirow{2}{*}{0.412} \\
\hline & & 0.962 & 1 & 0.962 & 20.71 & \\
\hline \multirow{9}{*}{ Right posterior } & \multirow{2}{*}{ P8 } & 1.54 & 1 & 1.54 & 0.387 & \multirow{2}{*}{0.652} \\
\hline & & 0.647 & 1 & 0.647 & 0.051 & \\
\hline & \multirow{2}{*}{ T8 } & 0.87 & 1 & 0.87 & 0.60 & \multirow{2}{*}{0.501} \\
\hline & & 0.83 & 1 & 0.83 & 0.25 & \\
\hline & \multirow{2}{*}{ P4 } & 0.427 & 1 & 0.427 & 0.38 & \multirow{2}{*}{0.287} \\
\hline & & 0.405 & 1 & 0.405 & 0.18 & \\
\hline & \multirow{2}{*}{ C4 } & 0.306 & 1 & 0.306 & 0.15 & \multirow{2}{*}{0.325} \\
\hline & & 0.37 & 1 & 0.37 & 0.054 & \\
\hline & $\mathrm{O} 2$ & 1.452 & 1 & 1.452 & 0.127 & 0.144 \\
\hline
\end{tabular}


Table 4. ANOVA test results of $\mathrm{H} 3$

\begin{tabular}{ccccccc}
\hline \multicolumn{2}{c}{ Brain Sites } & Sum of Squares & df & Mean Squares & F & Sig. \\
\hline \multirow{2}{*}{ Left anterior } & Fp2 & 0.043 & 1 & 0.043 & 1.23 & 0.876 \\
& F4 & 0.014 & 1 & 0.014 & 0.54 & 0.452 \\
\hline & F8 & 0.049 & 1 & 0.049 & 0.61 & 0.391 \\
\hline
\end{tabular}

Table 5. ANOVA test results of $\mathrm{H} 4$

\begin{tabular}{|c|c|c|c|c|c|c|}
\hline \multicolumn{2}{|c|}{ Brain Sites } & Sum of Squares & df & Mean Squares & $\mathbf{F}$ & Sig. \\
\hline & $\mathrm{Fp} 2$ & 0.0751 & 1 & 0.0751 & 1.98 & 0.513 \\
\hline \multirow[t]{2}{*}{ Left anterior } & F3 & 0.8540 & 1 & 0.8540 & \multirow[b]{2}{*}{0.537} & \multirow[b]{2}{*}{0.333} \\
\hline & F7 & 0.0996 & 1 & 0,0996 & & \\
\hline
\end{tabular}

PUNICAL PSYCH LOOY

the processing of negative emotional states takes place mostly in the occipital and temporal regions of the brain. These results illustrate the role of the lateral part of the hemispheres in the processing of various emotional states. So that positive emotions are mostly handled by the left hemisphere and negative emotions by the right hemisphere.

In the field of brain cortical activity, Azami and colleagues investigated the changing patterns considering extraversion and neuroticism personalities and found a significant inverse relationship between extraversion and activity of right posterior, frontal, and temporal ar- eas in basic status. Their results also indicate that, at the basic status, men showed more brain activities of right anterior, temporal, and posterior areas compared to these areas in women (Azami et al., 2013). Gable, Mechin, Hicks, and Adams (2015) found a significant direct relationship between positive urgency and the relative left frontal EEG activity. Through source localization, it was found that this relationship seemingly originated from decreased right frontal lobe activity in the inferior frontal gyrus. These findings revealed that the frontal asymmetry and positive urgency were associated with the decreased right frontal lobe activity.

Table 6. MANOVA test results of $\mathrm{H} 5$

\begin{tabular}{|ccccc}
\hline Brain Sites & Sum of Squares & df & F & Sig. \\
\hline Right frontal & 0.304 & 1 & 0.995 & 0.328 \\
\hline Left frontal & 0.086 & 1 & 0.571 & 0.572 \\
\hline Right anterior & 0.146 & 1 & 0.751 & 0.475 \\
\hline Left anterior & 0.112 & 1 & 0.142 & 0.852 \\
\hline Right parietal & 0.051 & 1 & 0.814 & 0.566 \\
\hline Left parietal & 0.027 & 1 & 1.41 & 0.118 \\
\hline Right temporal & 0.234 & 1 & 3.453 & 0.036 \\
\hline Left temporal & 0.041 & 1 & 2.872 & 0.045 \\
\hline Right posterior & 0.897 & 1 & 3.157 & 0.032 \\
\hline Left posterior & 1.079 & 1 & 2.932 & 0.014 \\
\hline
\end{tabular}


Table 7. MANOVA test results of H6 (PA)

\begin{tabular}{|ccccc}
\hline Area & Sum of Squares & df & F & Sig. \\
\hline Right frontal & 0.309 & 1 & 0.098 & 0.328 \\
\hline Left frontal & 0.072 & 1 & 1.068 & 0.954 \\
\hline Right anterior & 0.320 & 1 & 1.619 & 0.245 \\
\hline Left anterior & 0.078 & 1 & 2.274 & 0.218 \\
\hline Right parietal & 0.046 & 1 & 0.746 & 0.867 \\
\hline Left temporal & 1.456 & 1 & 1.150 & 0.638 \\
\hline Right posterior & 0.942 & 1 & 0.631 & 0.510 \\
\hline Left posterior & 1.557 & 1 & 0.870 & 0.446 \\
\hline
\end{tabular}

Additionally, it is reported that the prefrontal cortex is hemispherically specialized in motivation and affections. That is withdrawal behaviors and the experience of negative emotions result in the prevalent activity in the right areas compared to the left prefrontal areas, while the approach behaviors and positive affections result in the opposite patterns (i.e. dominant left vs. right activity) (Papousek, \& Schulter, 2014). The results of the above studies are valid and in line with the present study. In our study, there was a significant reverse relationship between the extraversion personality and activities of the occipital, frontal, and temporal regions of the right hemisphere. Besides, in the base state, there was an inverse relationship with the asymmetric cortical activity of the brain in the temporal lobe and the frontal lobe.

In an investigation, Mennella randomly assigned 32 right-handed females to obtain either the neurofeedback on frontal alpha asymmetry or an active control training. An increase in alpha asymmetry was observed in the asymmetry group which was caused by higher alpha wave activity at the right site $(\mathrm{P}<0.001)$, and also a

Table 8. MANOVA test results of H6 (NA) coherent reduction in both negative affect and anxiety symptoms $(\mathrm{P}<0.05)$ from pre- to post-training (Mennella, Patron \& Palomba, 2017). Heller declared that the higher left frontal activity compared to the right frontal activity represented the experience of pleasant affect, while the higher right frontal activity compared to the lower right frontal activity represented the unpleasant affect (Schmidtke \& Heller, 2004).

Since right cortical activity is more associated with negative emotions and extraversion people are described with features such as freshness, excitement, socialization, and so on, hence, higher extraversion tendencies in the individual are associated with a decrease in the activity of the brain regions associated with negative emotions. Our results are consistent with their findings, too. Also, our results indicate that the right anterior and right posterior region activities are not different in stable and neurotic people when NA induces them.

The present study compared left and right anterior and right posterior EEG activities and their relationship with four personality traits; extraversion, introversion,

\begin{tabular}{ccccc}
\hline Area & Sum of Squares & df & F & Sig. \\
\hline Right frontal & 0.081 & 1 & 0.509 & 0.624 \\
Left anterior & 0.215 & 1 & 0.121 & 0.905 \\
Right parietal & 0.043 & 1 & 0.354 & 0.197 \\
Left parietal & 0.031 & 1 & 0.521 & 0.61 \\
Left posterior & 0.128 & 1 & 0.782 & 0.096 \\
\hline
\end{tabular}


neuroticism, and stability. In conducting this study, we had these limitations. EEG recording locations were unsuitable because of hot weather and noise pollution. We had a problem in placing reference electrode, and due to the lack of the necessary hardware facilities, the vertex $(\mathrm{Cz})$ reference was selected as the reference electrode (placing on top of the head). The research group size was small due to the lack of cooperation of students to participate in the study. Some participants failed to comply with the conditions of the experiment (repeated eye blinking, etc.) despite giving instructions to them.

Based on the study results on 33 right-handed volunteer undergraduate students (17 males and 16 females), the activity pattern of all areas of the brain had changed in processing different emotional states, but some regions showed more changes which indicate the specificity of emotional processing location. According to the results, right hemisphere and particularly posterior regions are involved more in processing negative affections. Also, the personality dimension of individuals can affect the activity rate of some of these regions such that extraversion, compared to introversion, is associated with the reduction of cortical activity in the right hemisphere. We concluded that regional brain activity under positive and negative affect inductions is different, but gender has no effect on brain activity. Also, personality traits can affect the activity of some brain regions.

\section{Ethical Considerations}

\section{Compliance with ethical guidelines}

All ethical principles were considered in this article. The participants were informed about the purpose of the research and its implementation sages; They were also assured about the confdentiality of their information; Moreover, They were allowed to leave the sudy when ever they wish, and if desired, the results of the research would be available to them. The code of ethics has been issued by the Ethics Committee, Islamic Azad University of Neyshabur Branch in Iran (No. D 5274.93).

\section{Funding}

This paper was extracted from the master thesis prepared by Hamid Radsepehr which was approved in 2015 by Islamic Azad University of Neyshabur Branch in Iran.

\section{Authors' contributions}

All authors contributed in preparing this article.

\section{Conflict of interest}

The authors declared no conflict of interest.

\section{References}

Allen, J. J. B., Demeree, H. A., Mcknight, K. M., Moreno, F. A., \& Delgado, P. (2009). Alteration of frontal EEG asymmetry during tryptophan depletion predicts risk for future depression. Journal of Affective Disorders, 115(1-2), 189-95. [DOI: 10.1016/j. jad.2008.08.003]

Alessandri, G., Caprara, G. V., \& Pascalis, V. (2015). Relations among EEG-alpha asymmetry and positivity personality trait. Journal of Brain and Cognition, 97, 10-21. [DOI: 10.1016/j. bandc.2015.04.003]

Azami, S., Makvand Hosseini, Sh., Dokani, M., \& Zamirinejad, S. (2013). Brain cortical activity change patterns under positive and negative affective induction with consideration of extraversion and neuroticism. Journal of North Khorasan University of Medical Sciences, 5(4), 687-96.

Abolghasemi F. (2009). [Standardization of positive and negative emotions and its simultaneous validation with the mental health and vitality scales in Isfahan University students (Persian)] [MSc thesis]. Esfahan: University of Esfahan.

Alessandri, G., Caprara, G. V., \& De Pascalis, V. (2015). Relations among EEG-alpha asymmetry and positivity personality trait. Brain and cognition, 97, 10-21. [DOI:10.1016/j. bandc.2015.04.003] [PMID]

Allen, J. J., McKnight, K. M., Moreno, F. A., Demaree, H. A., \& Delgado, P. L. (2009). Alteration of frontal EEG asymmetry during tryptophan depletion predicts future depression. Journal of Affective Disorders, 115(1-2), 189-95. [DOI:10.1016/j. jad.2008.08.003] [PMID] [PMCID]

Azami S, Makvand Hosseini Sh, Dokani M, Zamirinejad S. (2013). [Brain cortical activity change patterns under positive and negative affective induction with consideration of extraversion and neuroticism (Persian)]. Journal of North Khorasan University of Medical Sciences, 5(4), 687-97. [DOI:10.29252/jnkums.5.4.687]

Brown KW, Goodman RJ, Inzlicht M. (2012). Dispositional mindfulness and the attenuation of neural responses to emotional stimuli. Social Cognitive and Affective Neuroscience, 8(1), 93-9. [DOI:10.1093/scan/nss004] [PMID] [PMCID]

Dehnabi A, Radsepehr H, Shareh H. (2017). Assessment of relationship between asymmetries EEG waves at baseline with Eysenck Personality traits. Biomedical and Health, 2(2), 74-82.

Davidson, R. J. (1992). Emotion and affective style: Hemispheric substrates. Psychological Science, 3(1), 39-43.

Dehnabi, A., Radsepehr, H., \& Shareh, H. (2017). [Assessment of relationship between asymmetries EEG waves at baseline with Eysenck Personality traits (Persian)]. Biomedical and Health, 2(2),74-82. 
Eysenck HJ, Eysenck MW. (1985). Personality and individual differences: A natural science approach. New York: Plenum Press. [DOI:10.1007/978-1-4613-2413-3]

Eysenck HJ, Eysenck SB. (1994 ). Manual of the Eysenck Personality Questionnaire:(EPQ-R Adult). San Diego: Educational and Industrial Testing Service.

Eysenck, H. J. (1974). Dimensions of personality. London: Routledge \& Kegan Paul.

Fakhari, A., Rostami, M., Nazari, M. A., Garoosi Farshi, M (2012). [Effects of mood induction on frontal asymmetry in individuals with behavioral activation/inhibition systems (Persian)]. Journal of Behavioral Sciences, 10(1),1-9.

Gable, P. A., Mechin, N. C., Hicks, J. A., \& Adams, D. L. (2015) Supervisory control system and frontal asymmetry: neurophysiological traits of emotion-based impulsivity. Social Cognitive and Affective Neuroscience, 10(10), 1310-5.[DOI:10.1093/ scan/nsv017] [PMID] [PMCID]

Georgiev, S., Minchev, Z., Philipova, D., \& Christova, C. (2008). Time-frequency spectral differences in event-related potentials between neurotic and stable persons in human EEG. International Journal Bioautomation, 11(Suppl.), 57-64.

Gable, P. A., Mechin, N. C., JHicks, J. A., \& Adams, D. L. (2015) Supervisory control system and frontal asymmetry: Neurophysiological traits of emotion-based impulsivity. Social Cognitive and Affective Neuroscience, 10(10), 1310-5. [DOI: 10.1093/scan/nsv017]

Georgiev, S., Minchev, Z., Philipova, D., \& Christova, C. (2008) Time-frequency spectral differences in event-related potentials between neurotic and stable persons in human EEG. Bioautomation, 11(Suppl), 57-64.

Goldberg D. (1978). Manual of the general health questionnaire nfer-nelson. Windsor: National Foundation for Educational Research.

Goldberg, D. P. (1988). User's guide to the general health questionnaire. Windsor: National Foundation for Educational Research.

Gomez, A., \& Gomez, R. (2002). Personality traits of the behavioural approach and inhibition systems: Associations with processing of emotional stimuli. Personality and Individual Differences, 32(8), 1299-316.[DOI:10.1016/S0191-8869(01)00119-2]

Hamann, S., Canli, T. (2004). Individual differences in emotion processing. Current Opinion in Neurobiology, 14(2), 233-8. [DOI:10.1016/j.conb.2004.03.010] [PMID]

Harmon-Jones, E., Lueck, L., Fearn, M., Harmon-Jones, C. (2006). The effect of personal relevance and approach-related action expectation on relative left frontal cortical activity. Psychological Science, 17(5), 434-40. [DOI:10.1111/j.14679280.2006.01724.x]

Heller, W. (1993). Neuropsychological Mechanisms Of Individual Differences In Emotion, Personality, and Arousal Neuropsychology, 7(4), 476-89. [DOI:/10.1037/08944105.7.4.476]

Kaviani, H., Pour Naseh, M., Moosavi, A. (2005). [Standardization and validation of the revised Eysenck personality inven- tory in Iranian population (Persian)]. Iranian Journal of Psychiatry \& Clinical Psychology, 11(3), 304-11.

Moghadas Tabrizi, Y., Mesbahi, E. (2015). [The relationship between the rest alpha asymmetry and the depression and anxiety symptoms of DASS-21 questionnaire (Persian)]. Psychological Research Quarterly, 6(1), 105-14.

Mennella R, Patron E, Palomba D. (2017). Frontal alpha asymmetry neurofeedback for the reduction of negative affect and anxiety. Behaviour Research and Therapy. 92(2), 32-40. [DOI:10.1016/j.brat.2017.02.002.]

Palahang, H., Nasr, M., Baraheni, M., Shahmohammadi, D. (1995). [Epidemiology of mental illnesses in Kashan City (Persian)]. Iranian Journal of Psychiatry \& Clinical Psychology, 2(4), 19-27.

Pascalis V, Cozzuto G, Caprara GV, Alessandri G. (2013). Relations among EEG-alpha asymmetry, BIS/BAS, and dispositional optimism. Journal of Biological Psychology, 94(1), 198-209. [DOI:10.1016/j.biopsycho.2013.05.016] [PMID]

Papousek, I., \& Schulter, G. (2002). Covariations of EEC asymmetries and emotional states indicate that activity at frontopolar locations is particularly affected by state factors. Psychophysiology, 39(3), 350-60. [DOI: 10.1017. S0048577201393083]

Reeve J. M. (2007). Translate of motivation and emotion [Y Seyed Mohammadi, Persian Trans.]. Tehran: Virayesh.

Revelle W., Scherer K, R. (2011). Personality and Emotion. Oxford: Oxford University Press.

Revelle, W., Scherer, K. R. (2008). Oxford companion to then affective sciences. Oxford: Oxford University Press.

Taghavi, M. (2001). [Evaluation of the validity of the General Health Questionnaire (G.H.Q) (Persian)]. Journal of Psychology, 20, 382-98.

Tomarken. A, J., Davidson, R. J., \& Henriques, J. B. (1990). Resting frontal brain asymmetry predicts affective responses to films. Journal of Personality and Social Psychology, 59 (4),791-801. [PMID: 2254854]

Schmidtke, J. I., \& Heller, W. (2004). Personality, affect and eeg: predicting patterns of regional brain activity related to extra version and neuroticism. Personality and Individual Differences, $36(3), 717-32$.

Watson, D., Clark, L. A., Tellegen, A. (1988). Development and validation of brief measures of positive and negative affect: The PANAS scales. Journal of Personality and Social Psychology. 54(6), 1063-70. [DOI:10.1037/0022-3514.54.6.1063] 
This Page Intentionally Left Blank 